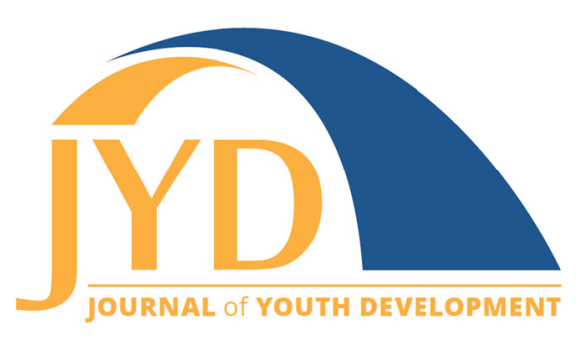

http://jyd.pitt.edu/ | Vol. 12 Issue 2 DOI 10.5195/jyd.2017.35 | ISSN 2325-4017 (online)

\title{
Empowering Processes of a Countywide Arts Intervention for High School Youth
}

\author{
Brad Forenza \\ Montclair State University \\ forenzab@mail.montclair.edu
}

\begin{abstract}
Arts interventions allow young people to address social problems and oppressive forces that impact their lives. Much research has explained the theory behind arts interventions; less has explored the organizational characteristics that may facilitate empowering processes for intervention consumers. The aim of this research is to contextualize dimensions of organizational empowerment in the context of a countywide arts intervention program. Retrospective, cross-sectional, in-depth interviews were conducted with 10 primary consumers of a countywide arts intervention for high school students. Directed content analysis of the interview data revealed ten emergent themes that transcended the data inductively. Findings support and extend our current understanding of organizational empowerment, as it relates to a countywide arts intervention program. Implications for policy, practice, and future research are discussed.
\end{abstract}

Key words: youth development, arts intervention, organizational empowerment, civic engagement

\section{Introduction}

Using the arts to promote healthy development and active citizenry can take myriad forms. In a review of empirical literature, Stuckey and Nobel (2010) explore the active and passive ways that arts interventions can positively impact individual wellbeing and community health. Spiro (2010) notes that arts interventions are "active" when consumers are integrated into the artistic experience (e.g. they perform); conversely, arts interventions are "passive" when consumers are receptors of an artistic experience (e.g. they watch a show). This research explores the active roles that primary youth consumers of a countywide arts intervention play in helping to facilitate a passive intervention experience for secondary youth consumers. The primary

\footnotetext{
(c)) EY New articles in this journal are licensed under a Creative Commons Attribution 4.0 License. This journal is published by the University Library System, University of Pittsburgh and is cosponsored by the University of Pittsburgh Press. The Journal of Youth Development is the official peer-reviewed publication of the National Association of Extension 4-H Agents and the National AfterSchool Association.
} 


\section{Empowering Processes of an Arts Intervention}

consumers of the focal intervention are high school youth who act in Reflections, an immersive, out-of-school, county-run improvisational theatre program. The secondary consumers of Reflections are its targeted, ad-hoc, youthful audiences. Utilizing an organizational empowerment framework, this research attempts to answer the following question: What empowering processes can an arts intervention program facilitate for active, primary consumers?

\section{Arts Intervention}

All societies share a desire to promote active citizenry and positive development among youth (Chauveron, Linver, \& Urban, 2016). Youth are faced with a host of oppressive forces in their everyday lives. These forces include racism, sexism, homophobia, poverty, victimization, domestic violence, substance abuse, mental illness, and criminality, as well as commonly identified youth issues like peer pressure and bullying (Cheng, Lo \& Weber, 2015; Haen \& Weil, 2010; Iyer-Eimerbrink, Scielzo \& Jensen-Campbell, 2015; Slayton, 2012). These forms of oppression are typically not addressed in targeted, pro-social, youth development initiatives like Scouts or 4-H (Forenza, 2016a). As Arnold and Cater (2011) note, those landmark programs were founded, in part, to thwart the anticipated deficiencies of youth development. Additionally, the topical and political natures of the oppressive forces experienced by youth (racism, sexism, etc.) often disqualify youth from discourse about them (Checkoway, 2012; Yates \& Youniss, 1999). Consequently, many youth are not equipped to tackle these issues that impede their everyday lives (Ginwright \& James, 2002). Yet young people are, in part, shaped by their ability to grapple with social issues in an effort to place themselves in a broader, societal context (Erikson, 1968; Flanagan \& Sherrod, 1998). Targeted, community-based arts interventions are one successful means of addressing social problems experienced by youth (Haen \& Weil, 2010). Prior research (Boon \& Plaistow, 2015; Schechner, 1977) asserts that societies have historically used the arts to address community problems and oppressive forces.

By affording young people the space to address social problems, questions, and solutions, arts interventions can offer a safe context for youth to critically examine their world (Conrad \& Sinner, 2015). Arts interventions can accentuate the social ecology of both the artist and his or her audience (Paget, 2014). At the individual level, Stern and Seifert (2009) indicate that those who are artistically involved (e.g. the active, primary consumers of a focal arts intervention) have higher levels of overall civic engagement. Their engagement may include expressing an opinion or advocating an idea through the presentation of one's art (e.g. an improvised scene about a topical issue). Additionally, arts interventions have proven to enhance a young person's 


\section{Empowering Processes of an Arts Intervention}

personal, spiritual, and social realms, as well as a young person's overall development (Litell, Kapitan, \& Torres, 2011). Other individual impacts of arts participation include the cultivation of confidence, self-esteem, emotional awareness, pro-social interests, skill development, and feelings of belonging (Paget, 2014).

At the community level, arts interventions may facilitate community empowerment for passive, secondary consumers (Lee, 2012). Community empowerment happens when individuals and organizations within a community "address conflicts within the community, and gain increased influence and control over the quality of life in their community" (Israel, Checkoway, Schulz, \& Zimmerman, 1994, p. 153). To the extent that being the passive recipient of an arts intervention can inspire one for social action, arts interventions are assumed capable of facilitating social change (Prentki, 2011; Slayton, 2012), and overall public health (Stuckey \& Nobel, 2010).

Much of the existing literature on arts interventions is theoretical (Stuckey \& Nobel, 2010). To date, there is almost no research exploring the potentially empowering characteristics of programs that facilitate arts interventions for their primary consumers, and even less research that incorporates youth voice as it relates to arts interventions. Through exploring programmatic and organizational dimensions, policymakers, practitioners, and scholars will better understand the processes that active, primary consumers experience when they engage in community-based arts intervention, and the ways in which these processes may impact youth development. This research utilizes an organizational empowerment framework in an attempt to discern the empowering processes that a countywide arts intervention may facilitate for its primary participants (high school youth who participate in a focal program).

\section{Organizational Empowerment}

Organizational empowerment is a conceptual framework that refers to "organizational efforts that generate psychological empowerment among members and organizational effectiveness needed for goal achievement" (Peterson \& Zimmerman, 2004, pg. 130). In other words, organizational empowerment can yield empowerment at the individual level (psychological empowerment), while also affecting some type of change. The term "organization" is used broadly to refer to any body of people (an intervention, club, program, etc.) tasked with a specific purpose. Four dimensions (shared beliefs, opportunity role structure, social support, and leadership) comprise intra-organizational empowerment, which refers to processes that happen within a focal intervention, club, or program. Both organizational and individual 
Empowering Processes of an Arts Intervention

(psychological) empowerment contribute to community empowerment by applying skills and resources towards collective goals (Israel et al., 1994).

Shared beliefs. Shared beliefs refer to group-based belief systems that should support individual members in achieving personal goals (Maton \& Salem, 1995). Research suggests that individuals are more likely to participate in a program or initiative if it is appealing to them (McAllum, 2014). According to McAllum (2014), young people who self-select to participate in an arts intervention are likely to be, on some level, artistically inclined. We assume they value the creative process, whether it is performance-based or otherwise. This assumption corroborates Forenza's (2016b) findings, whereby participants in a focal study had a valuesoriented motivation towards joining community theaters. Studies have also shown that sharing art in a public space presents opportunities for civic dialog (Lowe, 2000). To this end, shared beliefs among arts intervention participants may extend beyond a desire to perform and into realms that are more service-oriented.

Opportunity role structure. Opportunity role structure refers to an organization's internal capacity to facilitate the empowerment process (Maton \& Salem, 1995; Watts \& Flanagan, 2007). With respect to youth development programs, opportunity role structures may "engage young people in intentional, productive, and constructive ways while recognizing and enhancing their strengths" (youth.gov, (n.d.), "Effectiveness," para. 1). Research suggests that young people need opportunity role structures to make their voices heard (Jarrett, Sullivan, \& Watkins, 2005; Stoneman, 2002). In general, young people have opinions. Young people have perspective on the social problems that affect them (Checkoway, 2012), however, they often lack an infrastructure to address those problems (Yates \& Youniss, 1999). Under the auspices of a mentoring adult, arts interventions can extend niches for young people to fill and a channel through which to address focal issues.

Social support. Social support refers to the social context of an organization (Maton \& Salem, 1995). Arts interventions may facilitate social support when they (a) connect participating youth with similarly situated youth, as well as (b) connect participating youth with allied adults. With respect to youth-youth relationships, research indicates that positive peer interactions and acceptance is an important factor in determining one's commitment to an artistic cause (Kramer, 2005). Youth-youth interactions are tandem to Putnam's (2000) description of bonding social capital (the accumulation of intra-network solidarity). With respect to youth-adult relationships, the empirical literature refers to them as youth-adult partnerships (Zeldin, 2004; Zeldin, Petrokubi, \& MacNeil, 2008). Youth-adult partnerships are tandem to mentorship, which 


\section{Empowering Processes of an Arts Intervention}

can be vital to a young person's success (Leve, Fisher, \& Chamberlain, 2009). In the context of out-of-school programming for youth, both youth-youth and youth-adult partnerships may contribute to a young person's character development (Ettekal, Callina, \& Lerner, 2015).

Leadership. Maton and Salem (1995) also note that leadership is a process that may facilitate empowerment through (a) the direct action of a leader, and (b) a leader's indirect effect on organizational members. In the context of this research, "leadership" may refer to the founding coordinator of Reflections, who oversees the focal intervention. This mentoring adult is a paid professional who facilitates the actual intervention. Research on after-school programming notes that adult leaders have potential to facilitate social and personal development for youth (Durlak, Weissberg, \& Pachan, 2010). In addition to the direct action of an adult leader, leadership may also refer to the cultivation of initiative (Larson, 2000) among arts intervention participants. Initiative is, in part, defined by one's concentrated engagement with his or her social world. In the context of this research, leadership is explored as one dimension of organizational empowerment.

\section{Research Question and Aim}

In exploring dimensions of organizational empowerment for the active, primary consumers of a countywide arts intervention program, the author attempted to answer the following research question: What empowering processes can an arts intervention program facilitate for active, primary consumers? The research aim was to contextualize dimensions of organizational empowerment in the context of a countywide arts intervention program.

\section{Methods}

\section{Research Setting}

According to its recruitment flyer, Reflections is a "volunteer teen theater program that runs throughout the school year to prepare and present improvised scenes on a variety of topics and timely issues" (County of Bergen, 2015). In observing four of the program's "open" shows (shows not targeted at a particular audience) over a 10- year period, the author observed these "timely issues" to include racism, sexism, homophobia, and other oppressive forces. According to the founding coordinator:

We do a fair amount of education in Reflections so that the cast members are generally familiar with the topics on which they will 


\section{Empowering Processes of an Arts Intervention}

be performing. At times, we bring in guest speakers who specialize in a certain topic and the cast has a chance to have a dialogue with them and ask questions... The cast members do not need to be experts in all of the teen topics. They do, however, need to play the truth in the roles they take on, and respond to audiences from that character's point of view. (S. Block, personal interview, March 5, 2016)

Specifically, scenes are improvised for audiences and frozen at a point of conflict. Teen actors (the active, primary consumers of the intervention) remain in role while they have an interactive discussion with audience members, who are also teens (the passive, secondary consumers of this intervention). As the founding coordinator notes:

We do not bring the scenarios to a conclusion. We leave them open ended so that a discussion can take place (with audience members)... I also point out some resources for the audience members if they, or someone they know, needs help... It is my hope that audience members get to see parts of their own lives reflect on them. I want audience members to feel inspired enough so that they can talk freely to the characters created on stage and make comments and suggestions to them. By asking the characters questions... they also have the opportunity to help the characters problem solve a situation, and by doing so, can feel empowered in their own lives to make change. (S. Block, personal interview, March 5, 2016)

The Reflections program was developed 25 years prior to data collection by the founding coordinator, with the encouragement of the (then) county director of Family Guidance. After having seen an improvisational teen theatre troupe affiliated with a New York City-based mental health program, the director desired to build a similar program for youth in her county of Bergen, which is the most populated county in New Jersey (U.S. Census Bureau, n.d.). According to 2015 census estimates, the county is roughly $74 \%$ white/Caucasian; roughly $22 \%$ of residents are minors (under 18 ) and roughly $7 \%$ live below the federal poverty line. The focal program was developed in consultation with architects of the (now defunct) model New York City program, and with buy-in from the focal county's elected officials, at the time of its inaugural implementation, when participant interest was solicited from each of the school districts, vis-à-vis school administrators. 
As a result of 25 years of network building, middle and high school guidance counselors and teachers throughout the focal county's 70 municipalities now request Reflections performances at their school-wide assemblies and classroom events. Through the county's infrastructure, performances are also advertised and offered to juvenile detention centers, youth treatment centers, and alternative school environments that interface with the county's Department of Human Services. Through the founding coordinator's ingenuity, the program also performs for religious, civic, and nonprofit organizations, when invited.

\section{Research Design and Sample}

This research utilized a retrospective, cross-sectional, qualitative approach to explore the individual processes allied with a young person's participation in the Reflections program. ${ }^{1}$ Per agreement with the implementing county, only program alumni (as opposed to current cast members) could be recruited into this study. Consequently, a prospective study was never an option. Finally, a qualitative approach was employed to explore the depth of participant experiences (specifically, experiences related to organizational empowerment), as opposed to a desire to deductively test the relationship between one's perceived participation and his or her "levels" of organizational empowerment.

To recruit the most representative sample of primary consumers, and to ensure that all alumni had an equal opportunity of being selected into the sample, an email was sent to all prior cast members for whom the founding coordinator had accurate contact information. This sampling frame included 140 prospective participants, dating back to the inaugural cast of 1990 . To avoid selection bias, prospective participants were asked to contact the principal investigator (an outside researcher, unaffiliated with the program) expressing their interest in being a research participant. Sixteen individuals ( $11.4 \%$ of the sampling frame) responded in the affirmative. Of those initial 16, three did not respond to the principal investigator's follow-up emails; three more neglected to attend their scheduled interviews. This yielded a total of 10 research participants ( $7.1 \%$ of the sampling frame), which is congruent with the phenomenological tradition of small sampling (Creswell, 1998).

\footnotetext{
${ }^{1}$ Ethical Approval and Informed Consent: All procedures performed in studies involving human participants were in accordance with the ethical standards of the institutional research committee and with the 1964 Helsinki declaration and its later amendments or comparable ethical standards. Informed consent was obtained from all individual participants included in the study.
} 
Characteristics of these 10 participants are described in Table 1 . Participants were mostly male and mostly white/Caucasian. The racial/ethnic composition of the sample is slightly skewed from averages in the focal county, where $74 \%$ of all residents were exclusively white/Caucasian (U.S. Census Bureau, n.d.). Half the sample was still living in New Jersey at the time of interview (four of them were still living in the focal county where Reflections is implemented), while half were living in other states. Additionally, participants were roughly 28.6 years old at time of interview (median: 28 years old), and were roughly 10.6 years removed from high school (median: 10.0 years). On overage, participants had 2.7 years of continuous program involvement (median: 3.0).

\section{Procedure and Interview Questionnaire}

Per agreement with the implementing county, the author conducted interviews and transcribed them in real-time, on a laptop computer. Subsequently, the author repeated responses back to participants for accuracy. Per the implementing county, interviews were not audio or video recorded. Participants who lived locally $(n=5)$ were interviewed in person; participants who did not live locally were interviewed via telephone $(n=5)$. All participants received $\$ 20$ for their insight.

The open-ended questionnaire was organized around the four dimensions of intraorganizational empowerment (shared values, opportunity role structure, social support and leadership development). Patton (2001) found that the open-ended interview elicits deeper understanding of subjective experiences such as organizational empowerment among active, primary consumers of a countywide arts intervention. Queries such as "Why did you join Reflections?" "What are the program's goals?" and "What were your relationships like with other cast members and the founding coordinator?" guided the interview.

\section{Qualitative Analysis}

Analysis was guided by the research aim: to contextualize dimensions of organizational empowerment in the context of a countywide arts intervention program. First, responses were de-identified by the author and copied into an Excel spreadsheet (by question). The Excel spreadsheet was then given to two qualitatively trained graduate assistants for a preliminary round of a-priori coding, per question. After careful review of themes derived per-question, the author returned to the spreadsheet to conduct deeper, directed content analysis among 


\section{Empowering Processes of an Arts Intervention}

questions. Directed content analysis allows coding to be organized according to existing theory (Hsieh \& Shannon, 2005). To this end, emergent themes transcended the data, and are organized according to each of the four dimensions of organizational empowerment. According to Teddlie and Tashakkori (2009) saturation occurs when "the addition of more units does not result in new information" (p. 183). Interviews failed to illicit new information after the eighth interview. Creswell (1998) indicates that 10 units (the focal sample size) is the upperestimate for reaching saturation in a phenomenological study, such as this one.

Table 1. Characteristics of Reflections Alumni at Time of Interview $(N=10)$

\begin{tabular}{|c|c|c|c|}
\hline & & Frequency & Percent \\
\hline \multirow[t]{2}{*}{ Gender } & Male & 6 & 60 \\
\hline & Female & 4 & 40 \\
\hline \multirow[t]{2}{*}{ Race/Ethnicity } & White/Caucasian & 9 & 90 \\
\hline & Hispanic/Latino & 1 & 10 \\
\hline \multirow[t]{5}{*}{ Current Location } & New Jersey & 5 & 50 \\
\hline & Massachusetts & 2 & 20 \\
\hline & California & 1 & 10 \\
\hline & Florida & 1 & 10 \\
\hline & New York & 1 & 10 \\
\hline
\end{tabular}

\section{Trustworthiness}

Qualitative inquiry hinges on the researcher's ability to be reflexive-to be critical about his or her self-involvement in the study and the lens through which he or she sees the world. Consequently, the relationship between the author and the program's founding coordinator should be disclosed. While they are not colleagues (the author is a university faculty member and is unaffiliated with the implementing county), the author and founding coordinator are, in 


\section{Empowering Processes of an Arts Intervention}

fact, professional acquaintances. Both are social workers that believe in the capacity of artsbased interventions to function as a form of primary prevention and engagement for young people. In offering this disclosure, the author adheres to Patton's (2001) belief that establishing credibility is the bedrock for trustworthiness in qualitative research.

\section{Findings}

The aim of this research was to contextualize dimensions of organizational empowerment in the context of a countywide arts intervention program. To this end, this research sought to answer the question: "What empowering processes can an arts intervention facilitate for active, primary consumers?" Findings are summarized in Table 2 . One can see that emergent themes transcended the data inductively, and are organized according to the existing dimensions of organizational empowerment (shared beliefs, opportunity role structure, social support, and leadership). Findings are further explored below.

\section{Shared Beliefs}

In the context of organizational empowerment, shared beliefs refers to a group-based belief system that supports individual group members in achieving personal goals (Maton \& Salem, 1995). While participants first learned about Reflections via different means (several from printed advertisements, several from alumni of the group, two from prior program performances, and one from a school-wide mandate that students participate in a serviceoriented initiative), the majority of this sample $(n=9)$ indicated that they ultimately joined the program because of a desire to perform (the first emergent theme). "Freshman year I was getting in some trouble so I needed to go out and do something that I loved. I loved theater and improv," said one. "I loved to act, and Reflections seemed like a good fit," said another.

A deeper illustration of the shared belief in creative expression was explicated by all participants $(N=10)$, when they affirmed that acting in the program broadened their perspective and may have challenged audience assumptions about oppressive forces like racism and sexism. To quote one participant, "Reflections gave audience members an accessible means to explore sensitive topics." To quote another, "I wanted to teach the audiences something through improv." 
Table 2. Summary of Qualitative Findings by Theme and Subtheme

\begin{tabular}{|c|c|}
\hline $\begin{array}{l}\text { Dimension of Organizational } \\
\text { Empowerment }\end{array}$ & Emergent Theme \\
\hline \multirow[t]{3}{*}{ Shared Beliefs } & Desire to Perform \\
\hline & Broadened Perspective \\
\hline & Actor as Educator \\
\hline \multirow[t]{2}{*}{ Opportunity Role Structure } & Apolitical Context for Participation \\
\hline & Service-oriented Effort \\
\hline \multirow[t]{2}{*}{ Social Support } & Heightened connections \\
\hline & Feeling needed and valued \\
\hline \multirow[t]{3}{*}{ Leadership } & Importance of Founding Coordinator \\
\hline & Education for Life \\
\hline & Modeling Pro-social Behaviors \\
\hline
\end{tabular}

Another emergent theme, actor as educator, pertains to the belief among participants ( $N=10)$ that performing in the focal program allowed cast members (active, primary intervention consumers) to make a personal impact on potentially vulnerable or isolated audience members (passive, secondary intervention consumers). Below are two illustrations of this theme:

After a show on bullying-Reflections was a trailblazer in [addressing] bullying, by the way-during the questions at the end of the show, one audience member said, 'Where can I go, or who can I talk to, if this is happening to me?' He spoke up in front of everyone and connected with what we were presenting.

People [audience members] don't raise their hands if the questions are targeted at them. But if you ask something like 'Does anyone have a friend who has an eating disorder?' then 
Empowering Processes of an Arts Intervention

they all raise their hands and a conversation happens... You never know the depth of the impact, but you know there's an impact.

Shared beliefs enable group members to achieve personal goals. In this case, nine participants joined the program so they could perform improvised scenes on topical issues throughout the focal county. In having participated in the program, all participants developed a belief in their capacity to educate audiences.

\section{Opportunity Role Structure}

Opportunity role structures allow members to fill niches in a group (Maton \& Salem, 1995). Such niches can facilitate empowerment by assisting members in the achievement of personal goals through group participation. As previously mentioned, Reflections allows all participants the opportunity to act in improvised scenes. It also affords participants the opportunity to make an impact on audience members. In spite of facilitating impact (and, by extension, potentially facilitating change in an individual audience member), the majority of participants did not view themselves as "agents of change." Only two participants expressly viewed their program participation in political terms. For example:

Looking back (on my Reflections experience), there is a political aspect to it. We were really making everything very accepted by talking about it. By talking about these issues-sexual experimentation or whatever-we were accepting that they happened and that they were normal and that they should be addressed. We were not ignoring them as other circles would.

Considering the majority of participants $(n=8)$ did not view Reflections in political terms, a second emergent theme pertains to the perceived apolitical context for participation, whereby the recounted experiences of participation were divorced from anything related to effecting change in the civic or social spheres. This finding is contrary to the literature's general definition of "civic engagement," which broadly encompasses both service and activism (Flanagan \& Levine, 2010; Watts \& Flanagan, 2007). In spite of participating in a program whose mission includes "outreach," cast members in this study did not identify with the inherent politics of combatting stigma and oppressive forces. For example, "I never saw myself as a political actor," said one participant, "I prefer avoiding politics altogether," he concluded. Another participant offered, "I guess we changed the way people looked at their situations, but I never thought of 
Empowering Processes of an Arts Intervention

that as being political." Instead, program participation was viewed in apolitical terms, which is congruent with findings from other youth engagement research (see Forenza, 2016a).

Also similar to previous research is the finding that-among active, primary consumers of this intervention-what might be framed as political is, instead, framed as "community service." Indeed, all 10 participants described the program structure as a service-oriented effort, in spite of its anti-oppressive efforts.

\section{Social Support}

Feeling needed and valued by other group members is a significant reason for both joining and remaining a member of any group (Brodie et al., 2011). Social support afforded by an organization provides group members with pleasure and emotional fulfillment (McCarthy, Ondaatje, Zakaras, Brooks, 2004). Participants were unanimous $(N=10)$ in their feelings of heightened connections to fellow participants. These friendships were described as "Special bonds that I would not have made without Reflections," "Like coworkers, because we worked together," and "Unique, because none of my other friends had that Reflections experience."

Participants were approximately 10.6 years removed from high school and, consequently, the focal experience. As such, most conceded having lost regular contact with fellow cast members (though some also conceded that they stayed connected with fellow cast members via social media). Nevertheless, all participants indicated having heightened connections with fellow cast members during their Reflections tenure (one study participant ultimately met a spouse through the program). These heightened connections are notable when one considers that any given Reflections cast is comprised of individuals from all over the focal county, which includes 70 municipalities. It may have been unlikely for cast members-scattered about the county's 67 high schools-to have befriended each other without Reflections. As one participant observed, "In high school, you generally know people from your own town and that's about it. Reflections got me out of (my town) and got me to meet other people with similar interests."

Participants $(N=10)$ also described feeling needed and valued by the group for their individual contributions. Such contributions included "roles" that a cast member might play in an improvised scene, as well as functions she or he might occupy (allied with opportunity role structure) like being the provider of snacks at a given rehearsal, or a note-taker of rehearsal minutes. Such functions are illustrative of organizational empowerment's democratic structure 
(Israel et al., 1994), which may also contribute to one's sense of camaraderie and support within the group.

\section{Leadership}

Maton and Salem (1995) note that the leadership dimension of organizational empowerment may facilitate individual empowerment through (a) the direct action of a leader, or (b) a leader's indirect effect on organizational members. While the task mentioned above (providing snacks) may be conceived as a function of micro-level leadership, participants were unanimous $(N=10)$ in spotlighting the importance of the founding coordinator as charting an overall vision for the group. The founding coordinator was stated to be a mentor $(N=10)$, who led by example, was respectful, and was professional. "I felt closer with (the founding coordinator) than with any of my teachers, but-at the same time-I knew I was not her 'friend.' The boundaries were always very clear, but I knew I could talk with her about anything."

More than half of the sample $(n=6)$ indicated having received letters of recommendation (for college, employment, etc.) from the founding coordinator. A majority of participants ( $n=8$ ) further described (without prompt or coaxing) the organizational expectations charted by the founding coordinator. "The rules were pretty rigid, which-in hindsight-I appreciate," said one participant. Among the eight who discussed them, these "rules" or "codes of conduct" have become education for life (a final emergent theme). Such rules have traveled with participants into their adult, professional spheres, and are demonstrative of both (a) the direct action of a leader, and (b) the leader's indirect effect on organizational members. The education for life that participants described included: being punctual, reliable, and professional-expectations that are useful for any realm. As one participant explained:

I hope one day (the founding coordinator) will consider me a

friend... She gave me such confidence... Because of the responsibility she instilled-like her absence policy-I learned to be on time; to always be somewhere when I said I was going to be... she taught me improv, but she also taught me responsibility.

Education for life is also reflective of other youth engagement literature, which chronicles the sustained, pro-social outcomes of participating in extracurricular activities (see Eccles \& Barber, 1999). Education for life, and the quote above, are also illustrative of the impact an adult leader can have on overall youth development (Durlak et al., 2010). As evidenced by all interviews $(N=10)$, the founding coordinator was said to model pro-social behaviors. More importantly, 
Empowering Processes of an Arts Intervention

the standards she set for Reflections participants-the education for life that she afforded them-is both her enduring legacy and the legacy of the program itself for its active, primary consumers. "Reflections taught me a lot about myself," said one participant. "The expectations that (the founding coordinator) had for us prepared me for the professional world," said another. Through the founding coordinator's direct action, and through her indirect effect on organizational members, she is assumed to have facilitated individual empowerment for the 10 participants in this sample.

\section{Discussion}

Findings (summarized in Table 2) support and extend our current conceptions of organizational empowerment and its four dimensions. Findings contextualize these dimensions in the context of a countywide arts intervention program. Emergent themes that are illustrative of shared beliefs include: desire to perform, broadened perspective, and actor as educator. Emergent themes that are illustrative of opportunity role structure include: apolitical context for participation and service-oriented efforts. Findings related to social support are the notions of heightened connections with peers and feeling needed and valued by the group. Lastly, findings indicative of leadership include the importance of the founding coordinator, the notion of having been "educated for life," and having been privy to the modeling of pro-social behaviors by the founding coordinator.

\section{Limitations}

In an effort to probe for depth of experience, this research adheres to the qualitative tradition of small sampling (Patton, 2001). It is incorrect to make generalizations of these findings beyond the 10 program alumni who self-selected to participate in this study. Because these alumni self-selected to participate, they may constitute a biased sample. Similarly, the sample is mostly homogeneous in terms of race/ethnicity, and it is possible that racial/ethnic minorities might experience processes of arts intervention differently. Additionally, since participants were approximately 10.6 years removed from high school and their program experience, their recall may be spotty. While not an outright limitation, it is also important to remind the reader that the author and the founding coordinator are professional acquaintances; both inherently believe that arts-based intervention can function as primary prevention for young people. In disclosing the nature of their professional relationship and philosophical worldviews, the author seeks to maintain the reader's trust. In spite of these limitations, the author believes that this research 


\section{Empowering Processes of an Arts Intervention}

demonstrates an insightful collaboration between a university and its local government. In exploring the empowering processes of a countywide arts intervention program for active, primary intervention consumers, this research makes a valuable contribution to both the youth development and arts intervention literature. This study offers a formative exploration of what such interventions can actually offer to individual consumers and civil society alike. Chief among these offerings is the ability to address social problems and oppressive forces in a way that feels palatable for youth and their local communities.

\section{Implications}

Reflections operates in a single county in a single state. To the extent that it produces prosocial processes for the active, primary consumers interviewed for this study, policymakers might benefit from investing in similar arts-oriented interventions for the betterment of constituent wellbeing. Also, because of the safe, apolitical context of the program, policymakers themselves may benefit from using a Reflections-type model (also known as improvised scenes) to seek and receive input about constituent concerns from voices that may otherwise be silenced or oppressed in political discourse (e.g. youth). Of course, to do so necessitates additional time and resources dedicated from policymakers themselves, both of which are scarce.

While this research explored the individual processes of former cast members, there is a palpable perception among study participants that audiences (youth from the general population in the county, but also youth who interface with the county's Department of Human Services) profoundly benefit from watching a Reflections show. To the extent that this is true, practitioners will benefit from the perception among participants that arts-oriented interventions-specifically dramatic ones-are capable of facilitating pro-social processes for cast members and audiences alike. Practitioners in the human services who are not currently engaged in arts intervention will benefit from learning about this safe, "apolitical" way to explore social problems and oppressive issues.

Future research must examine the individual processes of arts interventions with larger samples. To yield a larger sample, however, requires more programs like Reflections. If one were to sample only current cast members, the program would need to exist in more than one county, and increase its scale. New Jersey has 21 counties; if each county had a Reflections program (and if each program had at least 20 cast members per year), there might be enough current cast members to acquire a robust sample at a single point in time. With a robust 


\section{Empowering Processes of an Arts Intervention}

sample, future research could examine both processes and outcomes associated with arts interventions in a more generalizable, representative way. Increasing scale is unlikely, however, in a political climate characterized by scarce resources for the prevention sciences.

Finally, future research must incorporate the voices of passive, secondary intervention consumers (audiences). These individuals likely experience their own processes and outcomes associated with being privy to a Reflections show. Since audiences may be system-involved (child welfare, juvenile justice, etc.) youth, it would behoove subsequent researchers to ask research questions like "What is the perceived impact that this program can have on audience members?" Similarly, evaluators may wish to incorporate the voices of guidance counselors and program managers who "book" shows, vis-à-vis the question, "What dialog can arts interventions facilitate that classroom discussion cannot?" Incorporating this perspective may help discern the extent to which the learning objectives from a focal Reflections show were actually met. Finally, evaluators can incorporate the voices of cast member parents and guardians. How did their children grow and change as a result of participation? Or, more specifically, what type of citizens did their children become? To this end, evaluators can probe for parent/guardian perceptions, as well. Finally, future research must incorporate the voices of underrepresented groups. Most participants in this study viewed their Reflections involvement as apolitical. Perhaps this finding is attributed to their status as members of privileged racial/ethnic groups. Future research questions may seek to answer "In what ways do minority and majority youth perceive arts intervention as political?"

\section{References}

Arnold, M. E., \& Cater, M. (2011). From then to now: Emerging directions for youth program evaluation. Journal of Youth Development, 6(3), 83-94.

Boon, R., \& Plaistow, J. (Eds). (2015). Theatre and empowerment: Community drama on the world stage. Cambridge: Cambridge University Press.

Brodie, E., Hughes, T., Jochum, V., Miller, C., Ockenden, N., \& Warburton, D. (2011). Pathways through participation: What creates and sustains active citizenship? Summary Report. London: United Kingdom.

Chauveron, L. M., Linver, M. R., \& Urban, J. B. (2016). Intentional self regulation and positive youth development: Implications for youth development programs. Journal of Youth Development, 10(3), 89-101. 
Journal of Youth Development | http://jyd.pitt.edu/ | Vol. 12 Issue 2 DOI 10.5195/jyd.2017.35

Empowering Processes of an Arts Intervention

Checkoway, B. (2012, October). Youth empowerment. Lecture presented by the University of Michigan School of Social Work, Ann Arbor.

Cheng, T. C., Lo, C. C., \& Weber, J. (2015). Community's role and school's role in protecting against student substance use: A spatial analysis. Journal of Child \& Adolescent Substance Abuse. 24 (4). 198-206.

Conrad, D., \& Sinner, A. (2015). Creating together. Waterloo, ON: Wilfrid Laurier University Press.

County of Bergen, Department of Human Services, Division of Family Guidance. [viewed 26 April 2017]. Reflections recruitment flier. Retrieved from: http://www.co.bergen.nj.us/DocumentCenter/View/187

Creswell, J. W. (1998). Qualitative inquiry and research design: Choosing among five traditions. Thousand Oaks, C.A.: Sage.

Durlak, J. A., Weissberg, R. P., \& Pachan, M. (2010). A meta-analysis of after-school programs that seek to promote personal and social skills in children and adolescents. American Journal of Community Psychology, 45(3-4), 294-309.

Eccles, J. S., \& Barber, B. L. (1999). Student council, volunteering, basketball, or marching band: What kind of extracurricular involvement matters? Journal of Adolescent Research, 14(10), 10-43.

Erikson, E. H. (1968). Identity: Youth in crisis. New York: Norton.

Ettekal, A. V., Callina, K. S., \& Lerner, R. M. (2016). The promotion of character through youth development programs: A view of the issues. Journal of Youth Development, 10(3), 6-13.

Flanagan, C., \& Levine, P. (2010). Civic engagement and the transition to adulthood. The Future of Children, 20(1), 159-179.

Flanagan, C. A., \& Sherrod, L.R. (1998). Youth political development: an introduction. Journal of Social Issues, 54(3), 447-456.

Forenza, B. (2016a). Opportunity role structure, social support, and leadership: Processes of foster youth advisory board participation. Journal of Community Psychology, 44(7), 904-918.

Forenza, B. (2016b). Sustained community theater participation as civil society involvement. Nonprofit and Voluntary Sector Quarterly. doi: 10.1177/0899764016660385.

Ginwright, S., \& James, T. (2002). From assets to agents of change: Social justice, organizing, and youth development. New Directions for Youth Development, 2002(96), 27-46.

Haen, C. \& Weil, M. (2010). Group therapy on the edge: Adolescence, creativity, and group work. Creative Arts Therapy. 34(1). 37-52.

Hsieh, H. \& Shannon, S. E. (2005). Three approaches to qualitative content analysis. Qualitative Health Research, 15, 1277-1288.

Israel, B., Checkoway, B., Schulz, A., \& Zimmerman, M. (1994). Health education and community empowerment: Conceptualizing and measuring perceptions of individual, organizational, and community control. Health Education Quarterly, 21(2), 149-170. 
Empowering Processes of an Arts Intervention

Iyer-Eimerbrink, P. A., Scielzo, S. A., \& Jensen-Campbell, L. A. (2015). The impact of social and relational victimization on depression, anxiety, and loneliness: A meta-analytic review. Journal of Bullying and Social Aggression. 1(1).

Jarrett, R. L., Sullivan, P. J., \& Watkins, N. D. (2005). Developing social capital through participation in organized youth programs: Qualitative insights from three programs. Journal of Community Psychology, 33(1), 41-55.

Kramer, M. W. (2005). Communication and social exchange processes in community theater groups. Journal of Applied Communication Research, 33(2), 159-182.

Larson, R. W. (2000). Toward a psychology of positive youth development. American Psychologist, 55(1), 170-183.

Lee, R. C. (2012). Eve Ensler's The Vagina Monologues as Feminist Activist Ecology (doctoral dissertation). Retrieved from Iowa State University digital repository: http://lib.dr.iastate.edu/etd/12763/

Leve, L. D., Fisher, P. A., \& Chamberlain, P. (2009). Multidimensional treatment foster care as a preventive intervention to promote resiliency among youth in the child welfare system. Juvenile Perspectives, 776), 1869-1902.

Litell, M., Kapitan, L., \& Torres, A. (2011). Creative art therapy in a community's participatory research and social transformation. Art Therapy: Journal of the American Art Therapy Association. 28(2). 64-73.

Lowe, S. S. (2000). Creating community art for community development. Journal of Contemporary Ethnography, 29(3), 357-386.

Maton, K. I., \& Salem, D. A. (1995). Organizational characteristics of empowering community settings: A multiple case study approach. American Journal of Community Psychology, 23(5), 631-656.

McAllum, K. (2014). Meanings of organizational volunteering: Diverse volunteer pathways. Management Communication Quarterly, 28(1) 84-110.

McCarthy, K. F., Ondaatje, E. H., Zakaras, L., \& Brooks, A. (2004). Gift of the muse: Reframing the debate about the benefits of the arts. Santa Monica, CA: RAND Corporation.

Paget, P. (2014). Locating a place for the arts within the art of child and youth care practice. Child \& Youth Services. 35(1). 46-60.

Patton, M. Q. (2001). Qualitative Research and Evaluation Methods. $3^{\text {rd }}$ ed. Thousand Oaks: Sage.

Peterson, N. A., \& Zimmerman, M. A. (2004). Beyond the individual: Toward a nomological network of organizational empowerment. American Journal of Community Psychology, 34(1/2), 129-145.

Prentki, T. (2011). Theatre for development, theatre as development. Drama Australia Journal, 35(1), 3546.

Putnam, R. (2000). Bowling alone: The collapse and revival of American community. New York: Simon and Schuster. 


\section{Empowering Processes of an Arts Intervention}

Schechner, R. (1977). Essays on performance theory:1970-1976. New York: Drama Book Specialists.

Slayton, S. C. (2012). Building community as social action: An art therapy group with adolescent males. The Arts in Psychotherapy. 39(3). 179-185.

Spiro, N. (2010). Music and dementia: Observing effects and searching for underlying theories. Aging and Mental Health, 14(8), 891-899.

Stern M. J., \& Seifert S. C. (2009, January). Civic engagement and the arts: Issues of conceptualization and measurement. Retrieved from http://animatingdemocracy.org/sites/default/files/CE_Arts_SternSeifert.pdf

Stoneman, D. (2002). The role of youth programming in the development of civic engagement. Applied Developmental Science, 6(4), 221-226.

Stuckey, H. L., \& Nobel, J. (2010). The connection between art, healing, and public health: A review of current literature. American Journal of Public Health. 100 (2). 254-263.

Teddlie, C., \& Tashakkori, A. (2009). Foundations of mixed methods research: Integrating quantitative and qualitative approaches in the social and behavioral sciences. Los Angeles, CA: Sage.

U.S. Census Bureau. (n.d.). QuickFacts: Bergen County, New Jersey. Retrieved from: https://www.census.gov/quickfacts/table/PST045215/34003,34,00

Watts, R., \& Flanagan, C. (2007). Pushing the envelope on youth civic engagement: A development and liberation psychology perspective. Journal of Community Psychology, 35(6), 779-792.

Yates, M., \& Youniss, J. (1999). Roots of civic identity: International perspectives on community service and activism in youth. Cambridge: Cambridge University Press.

Youth.gov. (n.d.). Positive Youth Development Programs: Effectiveness. Retrieved from: http://youth.gov/youth-topics/effectiveness-positive-youth-development-programs

Zeldin, S. (2004). Youth as agents of adult and community development: Mapping the process and outcomes of youth engaged in organizational governance. Applied Developmental Science, $8(2)$, 75-90.

Zeldin, S., Petrokubi, J., \& MacNeil, C. (2008). Youth-adult partnerships in decision making: Disseminating and implementing an innovative idea into established organizations and communities. American Journal of Community Psychology, 41(3-4), 262-277. 